\title{
Out of the wasteland
}

\author{
Trish Groves deputy editor, BMJ
}

"On Margate Sands/I can connect/Nothing with nothing" wrote T S Eliot, while convalescing from what was called a nervous breakdown at the time. The Waste Land's most famous line, however, is its first: “April is the cruellest month." In this April week Jackie Hopson narrates her own journey through the wasteland of depression, and the cruelty she encountered along the way makes hard reading (doi:10.1136/bmj.d93). A suicide attempt in the early 1970 s led to incarceration where "it seemed that I was to be punished for my illness and sedated if I made demands." Gradually, though, marriage, motherhood, fluoxetine, and 23 years of therapeutic care have increased Jackie's ability to have a liveable life.

Psychotherapist Jeremy Holmes has learnt much from Jackie: "What she needed was validation, confirmation that the world does treat the mentally ill differently, and understanding that to be depressed is at best to live only partly... Painfully, Jackie has taught me how corrosive the 'division of suffering' between patient and doctor can be." He ends by warning that further fragmentation of psychiatric services may militate against long term therapeutic relationships where illness can be explored, accepted, and sequestered.

Targeted group psychotherapy did not, however, reduce the frequency or severity of self harm in the large randomised trial that examined this question (Assessment of Treatment in Suicidal Teenagers, ASSIST) (doi:10.1136/bmj.d682). In all, 366 adolescents aged 12-17 with at least two episodes of self harm in the past year were randomised to usual care or to six sessions of developmental group therapy with follow-up sessions as required over the next year (with a mean of 10.2 sessions actually attended). Groups used cognitive behavioural and other techniques to understand the events and emotions leading to self harm and to tackle poor peer relationships, bullying, and family problems. Counterintuitively, this did not cost significantly more than usual care by local child and adolescent mental health teams ( $£ 21781$ per person $v £ 15372, \mathrm{P}=0.132$ ), albeit with wide confidence intervals for the comparison $(95 \%$ CI -1416 to 10782 ).

Jonathan Green and colleagues find at least some cause for optimism in their trial. As the control group improved as much as the intervention group, their findings may indicate the benefits of usual care or even show that teenagers are growing out of self harm more quickly these days. Or, of course, they may simply show regression to the mean, a possibility the authors acknowledge.

Editorialist David Brent teases out the various elements of the available interventions for teenagers who harm themselves (doi:10.1136/bmj.d592). He suggests we now need a more personalised treatment model, but acknowledges that this is a tall order and quotes W H Auden's line that "all humans have prejudices of their own that can't be foreseen." So far, he concludes gloomily, if psychotherapy is "the art of wooing nature," then self harm behaviour in adolescents is a condition that has spurned all suitors.

Cite this as: $B M J 2011 ; 342: \mathrm{d} 2358$ 